\title{
A High Torque Segmented Outer Rotor Permanent Magnet Flux Switching Motor for Motorcycle Propulsion
}

\author{
Enwelum Mbadiwe I *, Erwan Sulaiman, and Ahmad Md Zarafi \\ Research Centre for Applied Electromagnetics, Universiti Tun Hussein Onn Malaysia, 86400 Batu Pahat, Johor Malaysia
}

\begin{abstract}
Electric scooters also known as electric motorcycle are viable and personal means of road transportation have been making their ways into the world markets now because in them, combustion engine with the use of fuel oil for propulsion have been completely eliminated for economic and environmental imperatives. Electric motor which converts electrical energy into mechanical energy is used to overcome the complication of combustion engine. As it is, everyone is opting for combustion engine free and fuel-less type of vehicle. For this reason, manufacturers have exhibited interest, making research on electric motor very attractive. Meanwhile, surface permanent magnet synchronous motor (SPMSM) has been successfully developed having output torque of $110 \mathrm{Nm}$, the assembly of motor lacked mechanical strength between the rotor yoke and the mounted permanent magnet (PM) which heats up during speed operation, resulting to poor performance. To overcome the challenges laced with SPMSM, this paper presents a novel design of 24 stator 14 pole outer rotor-permanent magnet flux switching motor (SORPMFSM) capable of high torque and high performance. It employs an unconventional segmented rotor which has short flux path flow. It also embraces alternate stator tooth windings to reduce material cost. Design specifications and restriction with input DC current are the same with SPMSM. The 2D-FEA by JMAG, version 14 is used to examine the performance of the proposed motor in terms of cogging torque, back-emf, average torque, power and efficiency. Preliminary results showed that torque, power output and efficiency of the proposed motor are $1.9 \mathrm{Nm}$ times, $5.8 \mathrm{~kW}$ times more than SPMSM and efficiency of $84 \%$ thus, can sustain acceleration for long distance travel.
\end{abstract}

\section{Introduction}

For more than a century now, combustion engine (CE) vehicles which include conventional motorcycles or scooters have used fuel oil to create energy for propulsion for road transportation [1-2]. As it is, cost of maintaining these complex engines with the gloomy fuel crises has been a major concern [3-4]. To reduce fuel consumption in conventional scooters, hybrid electric scooters (HES), also known as hybrid electric scooters have combined combustion engine and electric motor in inner rotor structure, to greatly minimize the intake of oil [5-6].

The four electric motor candidates viable for HES are permanent magnet direct current motor (PMDC), induction motor (IM), switched reluctance motor (SRM) and permanent magnet synchronous motor (PMSM) respectively. Meanwhile, there are different types of HES with various speed operating ranges from 40 to 65 kmph [7]. Obviously, these speed ranges are not suitable for long distance travels.

PMDC was used because of the advantages of simple control which was developed with the tendency of high torque but due to the problems of commutator and regular maintenance of brushes renders it not reliable for driving operation [8-9]. Induction motor has been employed in electric scooter propulsion due to its robustness, low maintenance and ability to operate in unfriendly environments. Unfortunately, it has fundamental limitation which lies on low efficiency at low speed-light load region, low starting torque and speed which cannot be easily changed [10].

Obviously, SRM does not contain permanent magnets, the operation of stators is the same as brushless DC motors. SRM is reliable, rugged and low cost with advantage of low maintenance [11-12]. SRMs have lower torque capability and are generally noisy. They are suitable for low cost, medium to high speed applications where controllability and noise/shaft torque ripple are not critical. The torque is produced by the predisposition of the rotor to adjust with excited stator pole. The path of torque created is an element of the rotor position with respect to the energized phase, and is independent of the current flow direction through the phase winding. Constant torque can be produced by aligning stator pole and phase's excitation with the rotor rotor position [13].

For PMSM, especially IPMSM, has the advantage of high torque density and power density, its design tends is very difficult as permanent magnet (PM) is inserted inside the rotor with assembly lacking mechanical strength thus, degrading the performance of motor for driving system [14-15].

\footnotetext{
* Corresponding author: mb.fkee.uthm@gmail.com
} 
While each of these electric motors has assisted in reducing fuel oil intake, emission of hazardous gas remains worrisome [16-17]. As a viable solution for complete elimination of the complex combustion engine with fuel oil together, high torque electric motor is crucially necessary due to economic imperatives. Meanwhile, surface mounted permanent magnet synchronous motor (SPMSM) [18-19] has been developed that has completely eliminated $\mathrm{CE}$ and the use of fuel oil from HES, thus pure electric scooter vehicle (ESV) in the following scooters: Kingday electric scooters, Aima electric scooters, Mobility electric scooter and Terra motors with operating ranges between $35-60 \mathrm{~km} / \mathrm{hr}$ and power output of $3 \mathrm{~kW}-5 \mathrm{~kW}$ respectively. However, the torque capability of the motor operates at low speed range thus, the continuous search for a high torque motors for high performance suitable for long distance travels. Figure 1 illustrates the growth demand of ESVs from 2014 - 2024 [20].

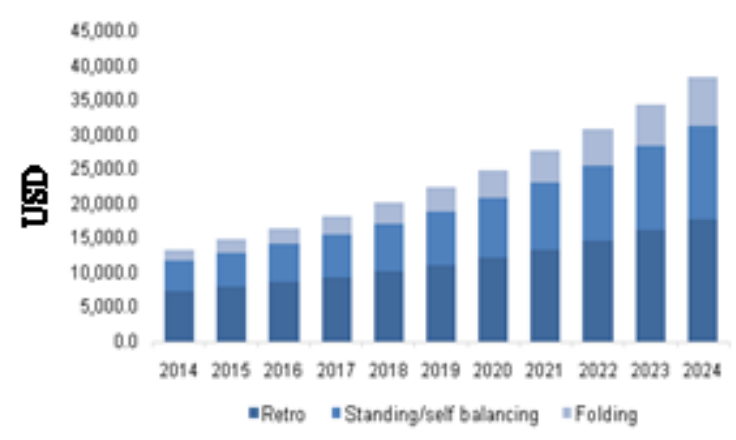

Fig. 1. Demands/brands of electric scooters

For this reason, research for a new motor with high torque capability is of importance. Meanwhile, surface mounted permanent magnet synchronous have been successfully developed with torque output of $110 \mathrm{Nm}$ and speed range of $100 \mathrm{~km} / \mathrm{hr}$ with $6 \mathrm{~kW}$ [21]. It consisted of 24 stator slots with single tooth armature windings but embracing surface mounted permanent magnet rotor. While SPMSM has exhibited longer speed range of travel, motor's torque of $110 \mathrm{Nm}$ cannot sustain acceleration for long distance travels as presented in figure 2 .

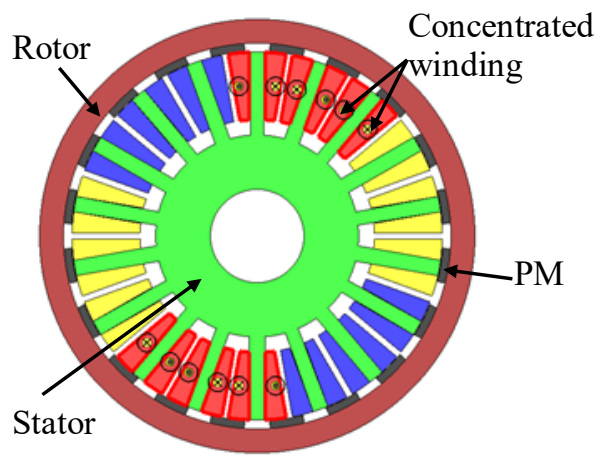

Fig. 2. Cross-sections of SPMSM
Meanwhile, the development of flux switching motor (FSM) [22-23], has turned around motor performance. FSM is a combination of the structures of SRM and induction machine (IM) but locates all active parts on the stationary stator only. It encompasses a new class of brushless motor that does not locate any active part on the rotating rotor, thus immaterial rotor. Obviously, FSM is the electric motor for high torque, high speed, high performance, constant power, simple cooling option, light-weight, high efficiency and cost competiveness.

In the main time, FSM has been applied in an aerospace, domestic appliances and automotive [24-25]. Furthermore, FSM is categorized into three sources of flux excitations namely, permanent magnet FSM, field excitation FSM and hybrid excitation FSM respectively.

To overcome the problems of SPMSM and its limitations, segmented outer rotor permanent magnet flux switching motor (SOR-PMFSM) for high torque electric scooter propulsion is presented.

\section{Research method}

The design restriction and parameter specifications of the proposed motor for electric scooter propulsion are the same with SPMSM as listed in Table 1. In the same vein, the electrical restrictions related with the inverter are set the same. Furthermore, the limit of the current density is maximum of $30 \mathrm{~A} / \mathrm{mm} 2$ for the armature coil. The outer radius of motor, stack length, and shaft radius of the target motor are the same with PMSM.

The motor design employed the commercial 2DFEA package, JMAG-Software version 14.1 released by Japan Research Institute (JNI). At first, the JMAG Geometry Editor to draw the rotor, stator, armature coil and permanent magnet respectively. Flow chart for design process is shown in figure 3 .

At the completion of the entire drawing, the motor is uploaded on the JMAG-Designer where materials, conditions, circuits and properties are set. The PM material used is NEOMAX-35AH having the residual flux density and coercive force at $20^{\circ} \mathrm{C}$ are $1.2 \mathrm{~T}$ and $932 \mathrm{kA} / \mathrm{m}$, the electrical steel $35 \mathrm{H} 210$ is used for rotor and stator parts. Additionally, the external rotor shaft is a non-ferromagnetic material of aluminium employed to secure the isolated segmented rotor members. Coil arrangement test was carried to affirm the operating principle of SOR-PMFSM. Furthermore, flux lines, flux distribution, cogging torque, induced back-emf voltage and finally, torque characteristics and efficiency were all examined. 


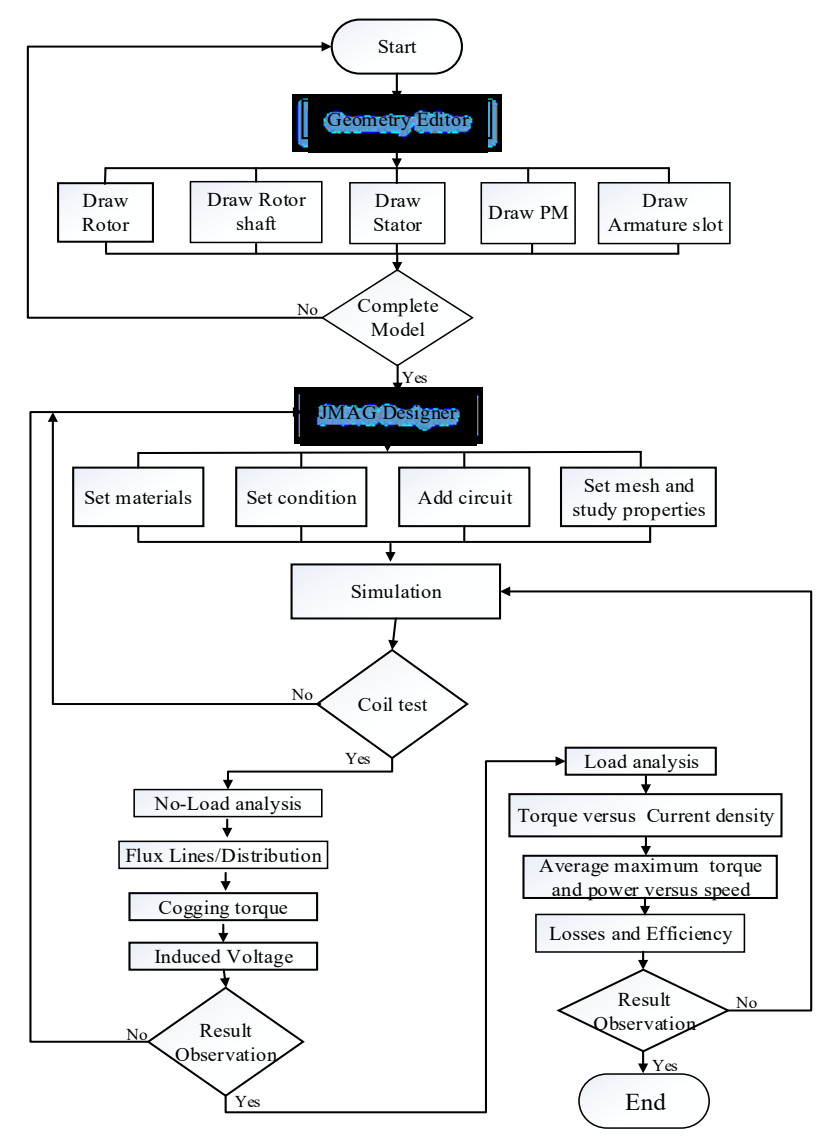

Fig. 3. Flow chart for design process

\subsection{Design motor parameters/rotor segment}

Each of the motor components such as rotor thus dimensioned as D1-D3, stator, PM D4-D5 and armature coil D6-D7 respectively were sketched in the JMAG Geometry Editor followed the process which was arranged as region mirror and region redial respectively as shown in figure 4. Stator topology with 12 slots limited to 7,8 and 10 segmented rotor pole and 24 stator slots limited to 10,14 and 22 segmented rotor pole respectively were investigated for three-phase to embrace two or four set of armature windings for the purpose of selecting the topology with optimal torque capability.

Moreover, the choice of rotor segment is significant to allow an appropriate permanence for the flow of flux. Already, some segmented rotor geometries have been considered as illustrated in figure 5. The shape in (a) shows an earliest circumferential extending pole applied in inner rotor synchronous reluctance machine [26]. Though circumferential extending pole is ideal in terms of performance in inner rotor configuration, it needs notable modifications for in-wheel/outer rotor application. However, to retain these segments for speed operation, design provision is necessary so that nonferromagnetic material is used to secure them without adding excessive load that will affect motor's performance. The modification led to dovetail structure in part (b) and the transerving design -
Table 1. Design dimension, electric supply and motor performance

\begin{tabular}{|c|c|c|}
\hline Descriptions & SPMSM & SOR-PMFSM \\
\hline No of phases & 3 & 3 \\
\hline No of rotor poles & 50 & 14 \\
\hline No of stator poles & 24 & 24 \\
\hline Motor radius (mm) & 139.7 & 139.7 \\
\hline Air gap length $(\mathrm{mm})$ & 0.5 & 0.5 \\
\hline PM mass $(\mathrm{kg})$ & 2 & 1 \\
\hline Stack length $(\mathrm{mm})$ & 100 & 100 \\
\hline Stator shaft $(\mathrm{mm})$ & 30 & 30 \\
\hline DC-voltage inver. $(\mathrm{V})$ & 415 & 415 \\
\hline Inverter current $\left(\mathrm{A}_{\mathrm{rms}}\right)$ & 360 & 360 \\
\hline Number of conductors & 18 & 18 \\
\hline Slot area (mm $\left.{ }^{2}\right)$ & 432 & 432 \\
\hline Avg. max. torque $(\mathrm{Nm}]$ & 110 & $>>110$ \\
\hline Power output (kW) & 6 & $>>6$ \\
\hline Rated speed (rev/min) & 1900 & 1900 \\
\hline
\end{tabular}

part (c) [27]. While the dovetail segment is applied in the FSM as compromise, it lacks the mechanical strength to be used for speed application. In order to overcome it, this proposed segment geometry provides a feature so that the segmented rotors will be properly secured using an external stator. Therefore, achieving this geometry follows the relationship that exists between length of an arc and segment of a circle using the convention given in Eqn. (1). Segment span, $\theta$ is calculated as:

$$
\theta=\frac{180 \times \text { rotor tooth width radius }(\mathrm{mm})}{\pi \times \text { inner rotor radius }(\mathrm{mm})}
$$

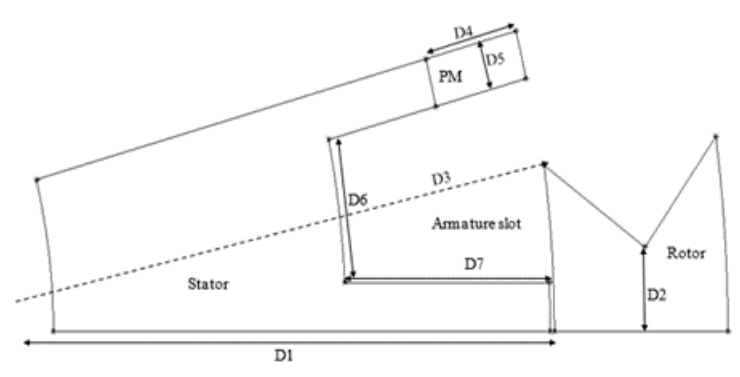

Fig. 4. Design motor parameters

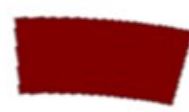

(a)

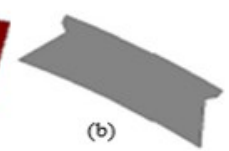

(b)

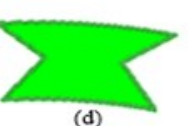

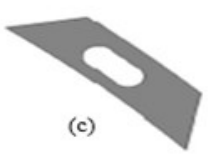

Fig. 5. Segmented rotors under consideration

Furthermore, completed motors are shown in figure 6. 


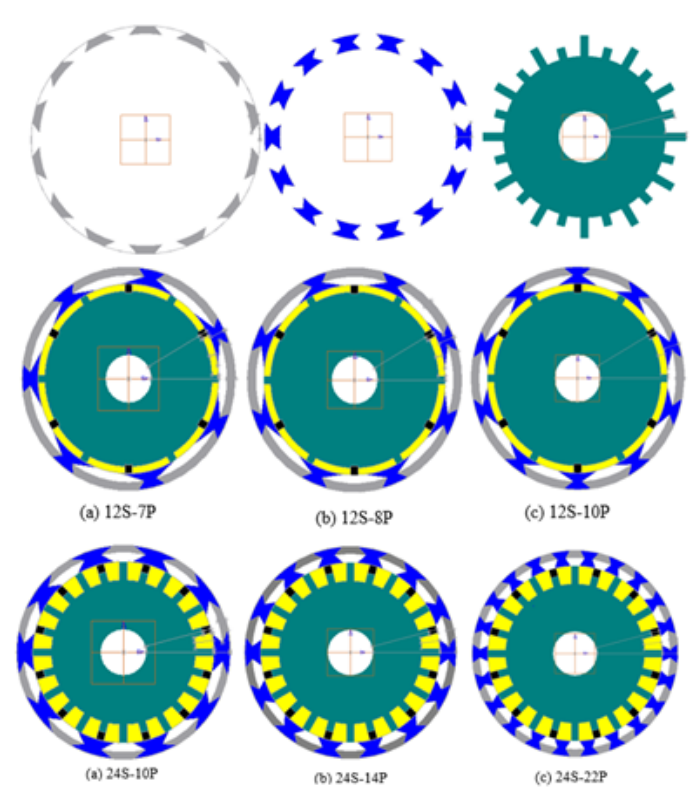

Fig. 6. Completed motors designed in Geometry Editor

\section{Results and discussions}

This section explained the results of research and at the same time, given the comprehensive discussion. Results are presented in figures, graphs that make the reader to follow through the process. The discussions are made in the following sub-topics.

\subsection{Coil test and operating principle}

Coil test was conducted on the proposed motor to properly set the correct position of each armature coil phase so as to confirm the operating principle of SOR-PMFSM. To accomplish this, a coil arrangement test examination was conducted on each armature coil separately to witness whether they were wound in the same direction or in opposite direction so that each coil phase would be correctly set in the same way. After this, the zero rotor position was clarified.

By comparing the flux linkages of different coils, the armature coil phases were defined according to conventional three-phase system. Figure 7 defines the Uphase flux linkage for each of the motors. Zero rotor position is the point in the $\mathrm{x}$-axis where the magnitude of $\mathrm{U}$ coil phase cuts it at $90^{\circ}$ and $270^{\circ}$ respectively. This confirms the operating principle.

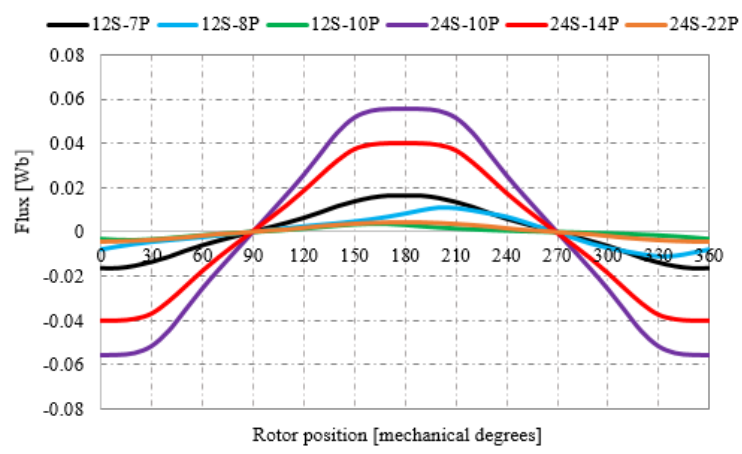

Fig. 7. U-phase of motors at various rotor poles with PM flux

\subsection{Cogging torque}

Cogging torque is the undesirable component that results to jerking of motor when value is high. For the proposed designs, the cogging torques with the PM flux source in open circuit are shown in figure 8. Taking a cursory look them all, 12S-10P has the highest peak-to-peak cogging torque with $48 \mathrm{Nm}$ and followed by $12 \mathrm{~S}-8 \mathrm{P}$ with $24 \mathrm{Nm}$. Other topologies have low cogging torque but $24 \mathrm{~S}-14 \mathrm{P}$ has favorable sinusoidal waveform which is considered more acceptable.

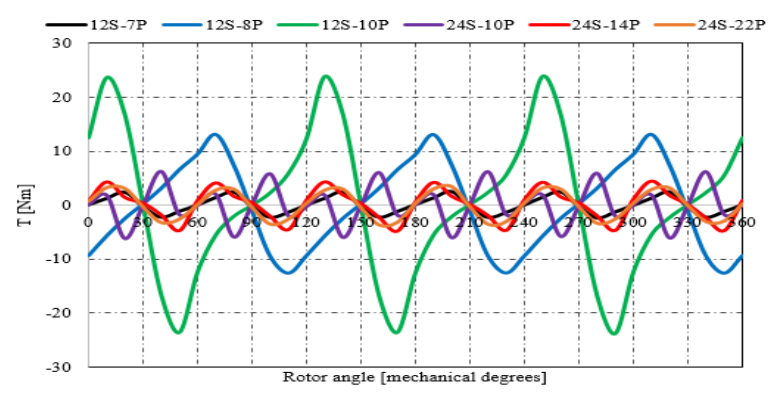

Fig. 8. Cogging of SOR- PMFSM

\subsection{Induced back-emf}

The motors induced emf presents the voltage generated due to PM only at the speed of $1900 \mathrm{rev} / \mathrm{min}$ are depicted in figure 9. From the plot, all the motors have induced back-emf which appeared distorted. Meanwhile, 24S-10P has the highest induced emf of $148 \mathrm{~V}$ followed by $24 \mathrm{~S}-14 \mathrm{P}$ of $110 \mathrm{~V}$. While $12 \mathrm{~S}-7 \mathrm{P}$ has emf amplitude of $48 \mathrm{~V}, 12 \mathrm{~S}-8 \mathrm{P}$ and $24 \mathrm{~S}-22 \mathrm{P}$ could not achieve sinusoidal waveform.

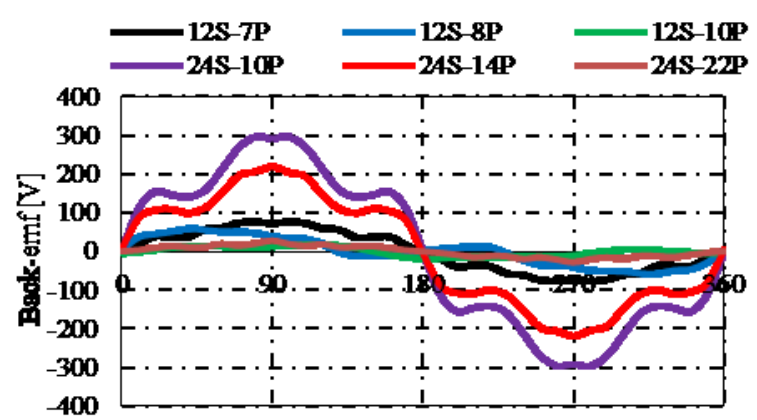

Rotor angle [mechanical degrees]

Fig. 9. Comparison of induced back-emf of SOR- PMFSM

\subsection{Load analysis}

To establish the best configuration, load analysis is conducted to examine torque performances of all the motors. At first, the maximum armature current density of $30 \mathrm{Arms} / \mathrm{mm}^{2}$ is injected into the circuit and the torque is investigated and analyzed. The results obtained for torque at various armature current density are plotted in figure 10. It is obvious that torque production of 24S-14P is the highest with $209 \mathrm{Nm}$ at the maximum 
armature current density. Meanwhile comparison of various torques obtained for the six topologies of SORPMFSM are provided in Table 2.

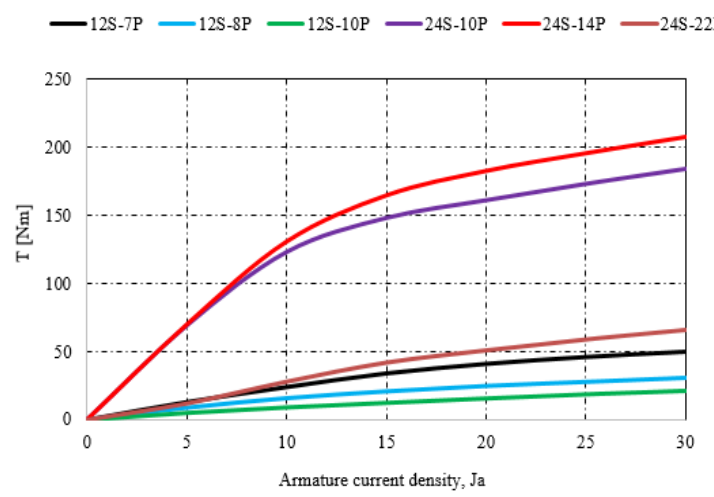

Fig. 10. Torque versus armature current density $\left(\mathrm{A} / \mathrm{mm}^{2}\right)$

Table 2. Comparison of torque capability of SORPMFSM topologies

\begin{tabular}{|c|c|c|}
\hline S.No. & $\begin{array}{c}\text { SOR-PMFSM } \\
\text { topologies }\end{array}$ & $\begin{array}{c}\text { Ave. output } \\
\text { torque (Nm) }\end{array}$ \\
\hline 1 & $12 \mathrm{~S}-7 \mathrm{P}$ & 50 \\
\hline 2 & $12 \mathrm{~S}-8 \mathrm{P}$ & 31 \\
\hline 3 & $12 \mathrm{~S}-10 \mathrm{P}$ & 21 \\
\hline 4 & $24 \mathrm{~S}-10 \mathrm{P}$ & 184 \\
\hline 5 & $24 \mathrm{~S}-14 \mathrm{P}$ & 209 (Highest) \\
\hline 6 & $24 \mathrm{~S}-22 \mathrm{P}$ & 66 \\
\hline
\end{tabular}

\subsection{Torque and power versus speed characteristics}

24S-14P topology of SOR-PMFSM was selected to examine the torque and power versus speed characteristics for securing the highest torque among the motors. Figure 11 shows the torque and power versus speed characteristics of the motor in which the power has increased from to almost $30 \mathrm{~kW}$ and remained constant throughout the speed operation at the base speed of $1374 \mathrm{rev} / \mathrm{min}$.

As shown in the plot, electric motors generate maximum torque at zero speed to pull away from a stop, for it uses a magnetic field to rotate. If applied a set current, a set torque is generated, thus maximum torque at zero speed. Furthermore, the power output is seen to be constant throughout the operating speed region.

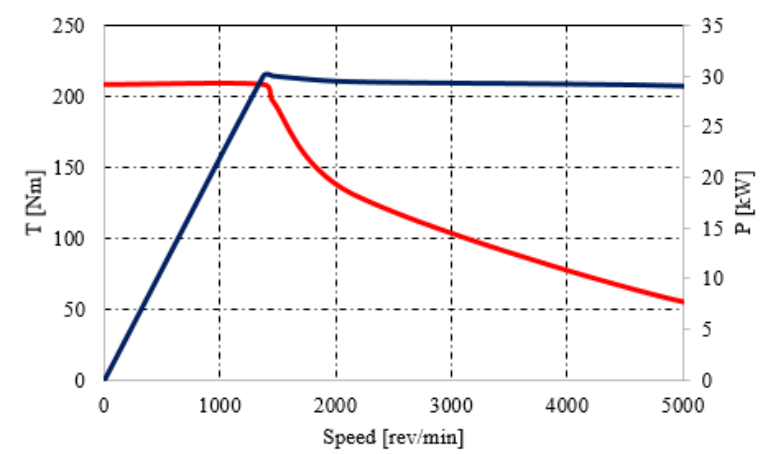

Fig. 11. Torque and power versus speed characteristics.

\subsection{Losses analysis and efficiency of $24 \mathrm{~S}-14 \mathrm{P}$}

Motor losses such as iron loss in all the laminated cores and copper loss in armature coil and the efficiency of $24 \mathrm{~S}-14 \mathrm{P}$ have been conducted and calculated on the basis of 2D-FEA. The specific operating points such as the maximum torque and highest speed at the operating points are chosen for motor's losses and efficiency analysis. The points are outlined in Figure 12. While points 1 and 2 are selected at maximum torque and highest speed, other operating points of 3 to 8 are selected at the speeds of $1000 \mathrm{rev} / \mathrm{min}, 2000 \mathrm{rev} / \mathrm{min}$ and $3000 \mathrm{rev} / \mathrm{min}$ respectively.

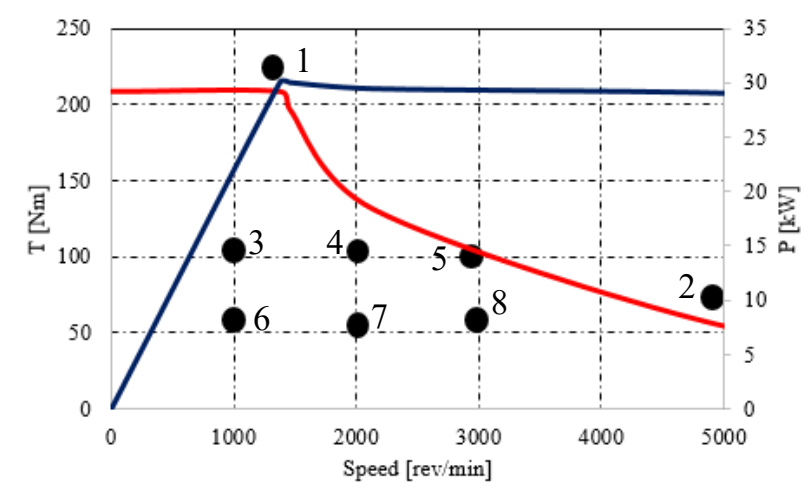

Fig. 12. Specific operating points for loss analysis

Table 3. Detailed loss analysis and motor efficiency of 24S14P SOR-PMFSM

\begin{tabular}{|c|l|l|l|l|l|l|}
\hline Point & $\begin{array}{l}\text { Pout } \\
(\mathbf{W})\end{array}$ & $\begin{array}{l}\text { Piron } \\
\text { (W) }\end{array}$ & $\begin{array}{l}\text { Pcopper } \\
(\mathbf{W})\end{array}$ & $\begin{array}{l}\text { Ptotal } \\
(\mathbf{W})\end{array}$ & $\begin{array}{l}\text { Eff. } \\
(\mathbf{\%})\end{array}$ \\
\hline 1 & 332328 & & 414.114 & 16482.66 & 349224.8 & 83.16 \\
\hline 2 & 196910 & & 3969.002 & 457.8516 & 201336.9 & 84.35 \\
\hline 3 & 100000 & & 72.53145 & 2770.735 & 102843.3 & 84.42 \\
\hline 4 & 200000 & 210.1237 & 2770.735 & 202980.9 & 85.18 \\
\hline 5 & 300000 & 396.203 & 2770.735 & 303166.9 & 85.0 \\
\hline 6 & 5000 & 54.87562 & 1354.508 & 51409.38 & 84.09 \\
\hline 7 & 10000 & 158.4833 & 1354.508 & 101513 & 85.28 \\
\hline 8 & 150000 & 293.2833 & 1354.508 & 151647.8 & 85.31 \\
\hline
\end{tabular}

Average Efficiency- $84.6 \%$

\section{Conclusion}

This paper has presented the performance characteristics of segmented outer rotor permanent magnet flux switching motor (SOR-PMFSM) for electric scooter capable of high torque. Six topologies were designed for comparison to select the topology with optimum performance. The 2D-FEA was by JMAG version 14 , to examine its characteristics. Topology 24S-14P gauged the lowest cogging torque, low induced back emf and highest torque. While the conventional SPMSM achieved maximum torque of $110 \mathrm{Nm}$, the proposed SOR-PMFSM outshines it by securing $209 \mathrm{Nm}$ which is 1.9 times higher. This preliminary result reveals that there are more gains using segmented rotor in terms of manufacturing cost, torque capability, stable power and 
high performance. This result is expected to improve during design optimization which will be reported soon. Therefore, SOR-PMFSM, serves a better motor for high torque and high performance for electric scooter propulsion.

The authors would like to thank Research, Innovation, Commercialization and Consultancy Office (ORICC) Universiti Tun Hussein Onn Malaysia (UTHM) for sponsoring this work

\section{References}

1. N. Ravi, S. Ekram, D. Mahajam, International Conference on Power Electronic, Drives and Energy Systems (ICPEDE), 1-4. (2006)

2. F. Zhan, L. Jin-hee Lee, C. You-young, K. Byung-il, International Conference on Electrical Machines and Systems (ICEMS), 949-953. (2013)

3. A. Boglietti, A. Cavagnino, A. Feraris, L.M. Lazzari, IEEE Industrial Electronics, 2 (4): 32-37. (2008)

4. W. Fei, P.C.K. Luk, J. Shen, Y. Wang, International Conference on Power Electronics Systems and Applications, (ICPES). (2009)

5. Y. Amamra, L. Vido, M. Gabsi, E. Hoang, F. Chabot, IEEE Vehicle Power Propulsion Conference (IEEE VPP), 58, (5) 1-6. (2006)

6. M. Z. Ahmad, E. Sulaiman, T. Kosaka, IEEE International Conference on Electrical Machines, (ICEM), pp. 691-696. (2015)

7. M. Alexander, Electric Power Research Institute, (EPRI), 2, 152. (2015)

8. K.T Chau, D. Zhang, J. Z. Jiang, C. Liu, Y. Zhang, IEEE Transactions on Magnetics (TOM), 43 (6), 2504-2506. (2007)

9. S.R. Macminn, T.M. Jahns, IEEE Transactions on Industry Application (TIA), 27, 997-1004. (1991)

10. M. Ehsanim, K.M. Rahman, H.A Toyilat, IEEE Transactions on Industrial Electronics, (TIE), 44,19-27, (1997)

11. R. E. Araujo, H. Teixeira, J. Barbosa, V. Leite, Proceedings of the IEEE International Symposium on Industrial Electronics (ISIE), 1499-1504, (2005)

12. D.P. Kothari, I. J. Nagrath, Electric Machines (Third Edition, Tata, McGraw-Hill Publishing Company, Copyright 2004, 508-509, (2004)
13. N. Bianchi, S. Bolognani, M. Zigliotto, IEEE Transactions on Industry Applications (AIE), 37, (5), 1348-1355, (2001)

14. C. T. Liu, K. C. Chuang, Conference on IEEE Transactions on Industry Application (IAS), 377383. (2002)

15. B. Kou, L. Chunyan, S. Cheng, IEEE Transactions on Plasma Science, (TPS), 39 (1), 511-511, (2005)

16. T. Raminosoa, M. Hamiti, M. Galea, C. Gerada, In Energy Conversion Congress and Exposition (ECCE), 298-2804. (2011)

17. S. I. Kim, G. H. Lee. J. P Hoang, T. U. Jung, IEEE Transaction on Magnetics (AIE), 44, (6), 15901593. (2008)

18. R. E. Araujo, H. Teixeira, J. Barbosa, V. Leite, Proceedings of the IEEE International Symposium on Industrial Electronics (ISIE), 1499-1504. (2005)

19. M. Risticevic, D. Iles, A. Moeckel, in International Symposium on Power Electronics, Electrical Drives, Automation and Motion (ISPEESAM), 221-225, (2016)

20. Electric Scooters Market By Product, Available http://www.grandviewresearch.com/industryanalysis/electric-scooters-market, (2014)

21. Eclimo-EB25 (n.d) Retrieved from http://techologicvehicles.com/en/details/920/eclimoeb25-prix-et-fiche-techinique, (2016)

22. Evans, A. Stevens, IEEE Conference on Electrical Machines (ICEM), (2010)

23. B. M. Song, K. C. Chang, J. Y. Choi, International Power Electronics Conference (ECCE), 2763-2742. (2010)

24. A. Affanni, A. Bellini, G. Franceschini, P. Guglielmi, C. Tassoni, IEEE Transactions on Industry Electronics (TIE), 52 (5), 1343-1349, (2005).

25. Fodorean, Daniel, L. Szabo, In IEEE Power Electronics, Electrical Drives, Automation and Motion, (PEEDAM). (2012)

26. A. Zulu, B.C. Mecrow, M. Armstrong, IEEE Trans. Industry Application (AIP), 48, (6), 2259-2267, (2012)

27. M. Galea M, Gerada C, Hamiti $\mathrm{T}$, In International Conference on Electrical Machines (ICEM). (2010) 